\title{
THE OUTCOME OF INFECTED ARTHROPLASTY OF THE KNEE
}

\author{
DAVID P. JOHNSON. GORDON C. BANNISTER
}

\author{
From the Bristol Knee Group, Winford Orthopaedic Hospital, Bristol
}

\begin{abstract}
In order to define the predisposing factors and outcome of infected arthroplasty of the knee, a retrospective analysis of a consecutive series of 471 knee arthroplasties was performed. There were 23 cases of superficial wound infection and 25 of deep infection. Superficial wound infection alone resulted in a painfree gait, with little limitation of movement. Rheumatoid arthritis, the use of constrained prostheses and the presence of a superficial wound infection, all predisposed to deep infection. Deep infection was eradicated by long-term antibiotics in only two patients in whom skin cover was successfully provided by a gastrocnemius musculocutaneous flap. Excision of a sinus track, wound debridement and exchange arthroplasty were universally unsuccessful. Arthrodesis, however, in 11 out of 12 cases, provided the painfree gait these patients desire.
\end{abstract}

Infection following arthroplasty of the knee is a serious complication, resulting in pain, discharge and loss of function. The incidence of deep infection in reported series is higher than that in hip arthroplasty, ranging from $0 \%$ to $5 \%$ in the majority of series. It is lower in association with conventional turbulent-flow operating theatres (Salvati et al. 1982), antibiotic prophylaxis, unconstrained prostheses (Insall et al. 1976), and in primary as compared with revision knee surgery (Cameron and Hunter 1982). Reports of the management of infected knee arthroplasty are sparse and emanate almost entirely from North America (Petty et al. 1975; Insall, Scott and Ranawat 1979; Eftekhar 1983).

\section{MATERIALS AND METHODS}

A retrospective analysis of a consecutive series of 471 knee arthroplasties with a minimum of one year's followup (mean 2.8 years) was undertaken. The operations were performed at Winford Orthopaedic Hospital, Bristol, over a five-year period. Infection was defined as clinical evidence of inflammation substantiated by a positive culture from a wound swab. The surviving infected cases were personally reviewed by the first author (DPJ).

Of the 471 arthroplasties performed, 152 were in patients with rheumatoid arthritis, while 316 had osteoarthritis. The operations were performed in a conventional turbulent-airflow operating theatre. Antibiotic prophylaxis consisted of cephradine $500 \mathrm{mg}$ by intra-

D. P. Johnson. FRCS. Orthopaedic Registrar

Nuffield Orthopaedic Centre. Headington. Oxford OX3 7LD. England. G. C. Bannister. MCh Orth. FRCS. Lecturer in Orthopaedics Bristol Royal Infirmary, Marlborough Street, Bristol BS2 8HW. Avon. England.

Requests for reprints should be sent to Mr D. P. Johnson.

( 1986 British Editorial Society of Bone and Joint Surgery $0301-620 \times 862057 \$ 2.00$ venous injection at induction of anaesthesia in the majority of cases, though cephazolin $1 \mathrm{~g}$ was used latterly. The dose was repeated eight hours and 16 hours postoperatively. A variety of prostheses was used, constrained, semiconstrained and unconstrained, the proportions of which are given in Table III. After operation the wounds were inspected frequently and a swab taken if any evidence of infection was apparent. Weight-bearing was usually begun within five days.

It was apparent that some infections followed a benign course while others resulted in failure of the arthroplasty; they have therefore been divided into two groups, superficial and deep. Superficial infection was considered to have occurred when clinical evidence of extracapsular inflammation was substantiated by a positive culture from a wound swab. Deep infection was defined as clinical evidence of deep inflammation, a positive swab culture and evidence from a sinogram or operation findings that the infection had spread to involve the prosthesis. Four knees clinically suspected of having a superficial infection and two knees clinically suspected of having deep infection were excluded because of repeatedly negative swab cultures. Statistical analysis was by the chi-squared and Fisher's exact tests.

\section{RESULTS}

The 471 arthroplasties were performed for 328 patients and resulted in 23 cases of superficial infection and 25 of deep infection. One hundred and fifty-two arthroplasties were performed for patients suffering from rheumatoid arthritis and 316 for patients with osteoarthritis. Rheumatoid arthritis was found to predispose significantly to the development of deep infection $(P<0.05)$. but not to that of superficial wound infection (Table I). There were 40 operations for revision of a previously non-infected arthroplasty; analysis showed that the incidence of deep infection was nearly four times as great as 
Table I. Incidence of infection and the type of arthritis

\begin{tabular}{lccccc} 
Diagnosis & $\begin{array}{l}\text { Number } \\
\text { of cases }\end{array}$ & $\begin{array}{c}\text { Superficial infection } \\
\text { Number }\end{array}$ & Per cent & Number & Per cent \\
\hline $\begin{array}{l}\text { Rheumatoid } \\
\text { arthritis }\end{array}$ & 152 & 7 & 4.6 & 15 & 9.9 \\
$\begin{array}{l}\text { Osteoarthritis } \\
\text { Other }\end{array}$ & 316 & 15 & 4.7 & 10 & 3.2 \\
Total & 3 & 1 & 33.3 & 0 & 0 \\
& 471 & 23 & 4.9 & 25 & 5.3
\end{tabular}

Table II. Incidence of infection in primary and revision arthroplasty

\begin{tabular}{|c|c|c|c|c|c|}
\hline \multirow[b]{2}{*}{ Operation } & \multirow{2}{*}{$\begin{array}{l}\text { Number } \\
\text { of cases }\end{array}$} & \multicolumn{2}{|c|}{ Superficial infection } & \multicolumn{2}{|c|}{ Deep infection } \\
\hline & & Number & Per cent & Number & Per cent \\
\hline $\begin{array}{l}\text { Primary } \\
\text { operations }\end{array}$ & 431 & 22 & 5.1 & 19 & 4.4 \\
\hline $\begin{array}{l}\text { Revision } \\
\text { operations }\end{array}$ & 40 & 1 & 2.5 & 6 & 15 \\
\hline Total & 471 & 23 & 4.9 & 25 & 5.3 \\
\hline \multicolumn{6}{|c|}{ Table III. The type of prosthesis used and the incidence of infection } \\
\hline & & \multicolumn{2}{|c|}{ Superficial infection } & \multicolumn{2}{|c|}{ Deep infection } \\
\hline Prosthesis & of cases & Number & Percent & Number & Per cent \\
\hline Stanmore & 39 & 3 & 6.1 & 8 & 25.1 \\
\hline Deane & 18 & 3 & 16.7 & 1 & 5.5 \\
\hline Sheehan & 173 & 7 & 4.0 & 12 & 6.9 \\
\hline Geomedic & 4 & 1 & 25.0 & 0 & () \\
\hline Kinematic & 101 & 7 & 6.9 & 2 & 2.0 \\
\hline St Georg & 98 & 2 & 2.0 & 1 & 1.0 \\
\hline Charnley & 38 & 0 & () & 1 & 2.6 \\
\hline Total & 471 & 23 & 4.9 & 25 & 5.3 \\
\hline
\end{tabular}

that in primary arthroplasty (Table II).

Seven different types of prosthesis were used in the series. The incidence of infection was found to be significantly higher when a constrained prosthesis was used $(P<0.01)$ (Table III). Of the 25 cases of deep infection, 14 occurred in the peri-operative period and 11 occurred after initially successful primary wound healing.

Superficial wound infection after operation predisposed to the development of deep infection $(P<0.001)$. Progression of the infection from an initially localised superficial wound infection to a proven deep infection was indicated by an initial negative sinogram or exploration. This occurred in seven of the 14 cases of perioperative deep infection. Of these seven cases, five suffered from rheumatoid arthritis.

Of the 11 cases of deep infection which developed late, two had a bacteriologically proven source from which haematogenous spread of infection to a previously healthy arthroplasty had occurred. One case followed a beta-haemolytic streptococcal sore throat, the other fol- lowed a Staphylococcus aureus urinary tract infection during a transurethral resection of the prostate. Subsequently the corresponding organism was isolated from the joint in both cases.

The infecting organism was found to be predominantly Staphylococcus aureus, although a variety of other bacteria were isolated (Table IV). The usually commensal organisms, Staphylococcus alhus and diphtheroids, were pathogenic in this situation. Superficial wound infection was treated by rest and antibiotics. Wound debridement and secondary wound suture were performed when indicated. All these patients walked without pain within five months; they had a final mean flexion deformity of 7 and a mean maximum flexion of 88 .

Table IV. Organisms cultured

\begin{tabular}{|c|c|c|}
\hline Organisms & $\begin{array}{l}\text { Superficial } \\
\text { infection }\end{array}$ & $\begin{array}{l}\text { Deep } \\
\text { infection }\end{array}$ \\
\hline $\begin{array}{c}\text { Staphylococcus: aureus } \\
\text { albus }\end{array}$ & $\begin{array}{r}7 \\
12\end{array}$ & $\begin{array}{r}13 \\
7\end{array}$ \\
\hline Streptococcus & 2 & 5 \\
\hline Diphtheroids & 0 & 1 \\
\hline Gram-negative bacilli & 2 & 3 \\
\hline Mixed infections & 1 & 4 \\
\hline
\end{tabular}

Deep infection was initially treated by immobilisation and antibiotic therapy in all cases. Flucloxacillin or sodium fusidate was the first-choice antibiotic. Alternative antibiotics or combination therapy was used when indicated by the sensitivity of the cultured organisms. The mean duration of antibiotic treatment was 1.3 years (range 0.1 to 4.9 years). Only two patients had resolution of their pain and discharge during this period. Thus longterm antibiotic treatment was successful in eradicating the symptoms of deep infection in only two of 25 cases $(8 \%)$.

In the treatment of deep infection, excision of a sinus track was performed four times; in each case the sinus recurred. Joint debridement, leaving the prosthesis in situ, was performed 27 times; in every instance it failed to eliminate the symptoms of deep infection. In an attempt to provide skin cover for an exposed prosthesis, split skin grafting was performed on two occasions, both unsuccessfully. However, a gastrocnemius musculocutaneous flap successfully provided permanent skin cover in two cases in which deep infection had been eradicated. A third case in which the infection had not been cleared up failed because of recurrent infection.

Exchange arthroplasty was attempted in two cases: in both the deep infection recurred. Subsequently one patient underwent an amputation and the other an arthrodesis. Amputation was undertaken in four of the 25 deeply infected cases. Subsequently all the amputees walked with the aid of a prosthesis. Arthrodesis was attempted in 12 cases by removal of the prosthesis and 
Table V. Results of salvage procedures

Author
Johnson and Bannister
Rand and Bryan
Insall et al.

Procedure

Arthrodesis

Two-stage replacement

Two-stage replacement

cement, followed by immobilisation with Charnley compression clamps supplemented by plaster. Subsequently, additional bone grafting was required to obtain bony ankylosis in two cases. Of the 12 cases, bony ankylosis was obtained in six after a mean duration of 10 months' immobilisation. More importantly, a painless knee during walking resulted in 11 of the 12 cases, since 5 of the 6 with fibrous ankylosis were painless. In one patient with fibrous ankylosis the knee remained moderately painful while walking.

Thus, of the 25 cases of deep infection four came to amputation and 12 to arthrodesis. There remain nine cases which have received long-term antibiotics and have not undergone amputation or arthrodesis. All these patients are handicapped by their knee and seven have an intermittent discharge from the knee. Five have painful knees and one patient requires mechanical assistance in order to transfer from bed to wheelchair. These nine patients had a mean fixed flexion deformity of 15 and a mean maximum flexion of 60 ; this is significantly less than those with a superficial infection $(P<0.001)$. Patients valued the ability to walk without pain more than joint movements or a pleasing cosmetic result; of the 25 cases, 17 have achieved this.

\section{DISCUSSION}

This study confirms the association of deep infection with the use of constrained prostheses (Insall et al. 1976), and suggests that rheumatoid arthritis, revision surgery and postoperative superficial wound infection are all predisposing factors.

Successful primary wound healing is of paramount importance as at least seven of the 25 cases of deep infection followed superficial wound breakdown. Failure of wound healing in rheumatoid patients is particularly disastrous as over $40 \%$ progressed to deep infection of the knee. Insall's deep infection rate of only $1.4 \%$ (Insall $e t$ al. 1979) is associated with a postoperative regimen of 10 days' immobilisation in extension, a much longer period than that used in this series. As rheumatoid patients were particularly prone to develop deep infection following superficial wound infection, immobilisation until the completion of wound healing seems appropriate in such cases.

Long-term antibiotics very rarely eradicate deep infection in a cemented prosthesis. They may suppress symptoms and reduce discharge but there is concurrent loss of bone stock and the pain, discharge and functional

$\begin{array}{llll}\begin{array}{l}\text { Interval } \\ \text { (weeks) }\end{array} & \begin{array}{l}\text { Number } \\ \text { of cases }\end{array} & \text { Painfree gait } \\ & 12 & 11 & 92 \\ 2 & 14 & 6 & 43 \\ 6 & 11 & 8 & 73\end{array}$

disability persist. Their use should be confined to patients who are too infirm for surgery and have limited life expectancy. It is not known whether long-term antibiotics are more successful for infected uncemented prostheses.

Treatment of an infected cemented knee prosthesis must aim to achieve a painless knee. Immediate exchange arthroplasty has proved to be unreliable; two-stage reimplantation arthroplasty has therefore been developed and appears more promising. However, when removal of the prosthesis was followed by replacement after two weeks, painless walking was obtained in only six of the 14 patients (Rand and Bryan 1983); these authors concluded that a two-week interval was insufficient. When the prosthesis was replaced after six weeks, painless walking was obtained in eight of 11 cases (Insall, Thompson and Brause 1983). At present arthrodesis offers the best chance of long-term painfree gait (Table V).

The surgical salvage of an infected cemented knee arthroplasty presents a choice between arthrodesis and two-stage replacement arthroplasty. Arthrodesis may not result in bony ankylosis and requires prolonged immobilisation, but it offers a reliable painfree result. At present two-stage replacement merits consideration only in patients with multiple joint involvement in whom loss of knee movement threatens their mobility and independence.

The authors would like to thank Mr A. H. C. Ratliff, Mr R. A. J. Baily and the surgeons of Winford Orthopaedic Hospital. Bristol. for their assistance.

\section{REFERENCES}

Cameron HU, Hunter GA. Failure in total knee arthroplasty: mechanisms, revisions and results. (lin Orthop 1982:170:141 6.

Eftekhar NS. Total knee-replacement arthroplasty: results with the intramedullary adjustable total knee prosthesis. J Bone Joint Surg $[A m]$ 1983:65 A:293 309.

Insall JN, Ranawat CS, Aglietti P. Shine J. A comparison of four models of total knee-replacement prostheses. J Bone Joint Surg $[A m]$ 1976:58 A:754 65.

Insall JN, Thompson FM, Brause BD. Two-stage reimplantation for the Salvage of infected total knee arthroplasty. J Bone Joint Surg $[\mathrm{Am}]$ 1983:65 A:1087 98.

Insall J, Scott WN, Ranawat CS. The total condylar knee prosthesis: a report of two hundred and twenty cases. J Bonc Joint Surg $[\mathrm{Am}]$ 1979:61 A:173 80.

Petty W, Bryan RS, Coventry MB, Peterson LFA. Infection after total knee arthroplasty. Orthop Clin North Am 1975:6(4): 100514.

Rand JA, Bryan RS. Reimplantation for the salvage of an infected total knee arthroplasty. J Bone Joint Surg $[\mathrm{Am}] 1983 ; 65$ A : I081 6.

Salvati EA, Robinson RP, Zeno SM, Koslin BL, Brause BD, Watson PD Jr. Infection rates after 3175 total hip and knee replacements performed with and without a horizontal unidirectional filtered airflow system. J Bone Joint Surg [Am] 1982:64 A:525 35. 